\title{
Paradoxos nos 'benefícios' aos incapacitados: biopolítica e saúde mental
}

Marciana Zambillo. Universidade Federal do Rio Grande do Sul

Analice de Lima Palombini. Universidade Federal do Rio Grande do Sul

Daniel Dall'Igna Ecker. Universidade Federal do Rio Grande do Sul

\section{Resumo}

Este ensaio objetiva problematizar os paradoxos dos 'benefícios' governamentais, cedidos aos indivíduos considerados incapacitados ao trabalho, devido algum diagnóstico em saúde mental. Para tanto, utiliza do conceito de Biopolítica, proposto por Michel Foucault, contrapondo a relatos de usuários e usuárias de serviços de saúde mental. Através dessas experiências, analisam-se impasses produzidos entre os princípios da Reforma Psiquiátrica Brasileira e os métodos utilizados pelos programas de seguridade social para garantia dos 'benefícios'. Na discussão, aponta-se que o paradoxo dos direitos se torna ainda mais intenso quando as reivindicações emancipatórias no campo da subjetividade estão localizadas numa sociedade em que os Direitos Sociais, previstos em Constituição, não foram conquistados pela maioria da população brasileira. Assim, se os 'benefícios' se colocam de forma paradoxal é, também, porque boa parte da população não tem direitos garantidos e precisam obter alimentação, moradia, saúde, dentre outros, à custa da manutenção de patologias como justificativa para garantir direitos.

Palavras-chave: saúde mental; emprego; seguridade social; biopolítica.

\begin{abstract}
The paradoxes of government 'benefits' in individual considered incapable: biopolitics and mental health. This essay aims to discuss the paradoxes of government 'benefits', given to individuals considered incapable of work, due to some diagnosis in mental health. For this, use the concept of Biopolitics, proposed by Michel Foucault, in opposition to reports of users of mental health services. Through these experiences, analyze impasses produced between the principles of the brazilian Psychiatric Reform and the methods used by the social security programs to guarantee benefits. In the discussion, it is pointed out that the rights paradox becomes even more intense when the emancipatory claims in the field of subjectivity are located in a society in which the Social Rights, foreseen in Constitution, were not won by the majority of the brazilian population. Thus, if the benefits are paradoxical, it is also because a large part of the population does not have guaranteed rights and needs to obtain food, shelter, health, among others, at the expense of maintaining pathologies as justification for ensure rights.
\end{abstract}

Keywords: mental health; employment; social security; biopolitics.

\section{Resumen}

Las paradojas de los 'beneficios' gubernamentales cedidos a los individuos considerados incapacitados: biopolítica e salud mental. Este ensayo objetiva discutir las paradojas de los 'beneficios' gubernamentales, cedidos a los individuos considerados incapacitados al trabajo, debido a algún diagnóstico en la salud mental. Para ello, se utiliza el concepto de Biopolítica, propuesto por Michel Foucault, en contrapunto a relatos de usuarios de servicios de salud mental. A través de esas experiencias, se analizan impasses producidos entre los principios de la Reforma Psiquiátrica brasileña y los métodos utilizados por los programas de seguridad social para garantizar los beneficios. En la discusión, se apunta que la paradoja de los derechos se vuelve aún más intenso cuando las reivindicaciones emancipatorias en el campo de la subjetividad están localizadas en una sociedad en la que los Derechos Sociales, previstos en la Constitución, no fueron conquistados por la mayoría de la población brasileño. Así, si los beneficios se plantean de forma paradójal es, también, porque buena parte de la población no tiene derechos garantizados y necesitan obtener alimentación, vivienda, salud, entre otros, a costa del mantenimiento de patologías como justificación para asegurar derechos.

Palabras clave: salud mental; empleo; seguridad social; biopolítica. 
Este ensaio ${ }^{1}$ tem como objetivo problematizar os paradoxos em torno dos 'benefícios'2 governamentais, cedidos aos indivíduos considerados incapacitados ao trabalho, devido a algum diagnóstico em saúde mental. Para tanto, utiliza do conceito de Biopolítica, proposto por Michel Foucault $(2005 ; 2008)$, contrapondo a relatos de usuários e usuárias de serviços de saúde mental, beneficiários ou não pelo governo brasileiro. Através das experiências, analisam-se impasses produzidos entre os princípios propostos pela Reforma Psiquiátrica Brasileira - que coloca a questão diagnóstica entre parênteses, extrapolando-a e investindo em uma atenção à saúde de forma ampliada e os métodos utilizados pelos programas de seguridade social para garantir o acesso a 'benefícios' monetários os quais ainda se fixam exclusivamente em classificações diagnósticas e nas incapacidades decorrentes dessas.

Os 'benefícios', assegurados em leis brasileiras às pessoas impossibilitadas de trabalhar devido a uma condição de saúde mental, podem ser de duas ordens: (a) assistenciais, destinadas àquelas que comprovem não possuir meios de prover a própria manutenção ou de tê-la provida por sua família; (b) previdenciários, para aquelas pessoas que contribuíram com o sistema de seguridade social ou são dependentes de contribuintes. São chamados, respectivamente, de 'benefício' assistencial para a pessoa com deficiência mental (Benefício de Prestação Continuada BPC - LOAS) e auxílio-doença ou aposentadoria por invalidez (Ministério da Previdência Social, 2017).

A obtenção do 'benefício' está condicionada à perícia médica sistemática, que analisa, a partir da categorização psiquiátrica, as características do adoecimento incapacitante relacionadas às condições de trabaIho. Com isso, o diagnóstico psiquiátrico se torna uma premissa, uma prerrogativa, para que os usuários da saúde mental tenham acesso, tanto aos direitos previdenciários, quanto aos direitos assistenciais relacionados à saúde mental (Constituição da República Federativa do Brasil. 1988, 5 de outubro; Lei Orgânica da Assistência Social - LOAS, n. 8.742, de 7 de setembro de 1993).

Ser considerado doente, isto é, ter um código referente a transtornos mentais ou comportamentais catalogado na Classificação Internacional de Doenças (CID), torna-se uma obrigatoriedade para se obter o 'benefício'. Contudo, garantir direitos sob patologização dos sujeitos tem se mostrado como o caminho oposto ao que se tem buscado produzir no campo da saúde mental, no que se refere à produção de autonomia e despatologização da vida. Princípios como "sou uma pessoa, não uma doença" (Onocko Campos, et al. 2012, p. 18) têm orientado as ações pautadas pelos valores da Reforma Psiquiátrica Brasileira (Lei n. 10.216, de 6 de abril de 2001) e das políticas de saúde mental que dela derivam. Nessas ações, visam-se priorizar aquilo que há de singular na existência dos sujeitos e não os reduzir a meras patologias ou categorias diagnósticas.

No Brasil, o campo da saúde, em especial a saúde mental, adota o conceito de autonomia com muito apreço, conforme explicitado em grande parte dos documentos que embasam as políticas públicas da área. Esse, apresenta-se como um dos princípios propostos pela Reforma Psiquiátrica, embora os documentos pressuponham um entendimento a priori ou naturalizado de autonomia, pouco problematizando o conceito e seus diferentes efeitos (Zambillo, 2015). A obtenção de 'benefícios' pela população usuária de serviços de saúde mental tem sido apontada como um auxílio financeiro importante, tanto na produção de autonomia do beneficiário, quanto como apoio para suas famílias ou seus cuidadores (Santin, 2011). A garantia dos direitos monetários previdenciários e assistenciais aos(as) usuários(as) de saúde mental deriva, portanto, da reivindicação do exercício de cidadania e pela manutenção de ações que produzam autonomização, contudo, atualmente, efetiva-se pela imposição do imperativo psicopatológico.

É no reconhecimento desse paradoxo que se propõe este ensaio. $\mathrm{O}$ conceito de biopolítica, proposto por Michel Foucault $(2005 ; 2008)$, possibilita problematizar os paradoxos em torno do 'benefício' concedido aos considerados incapacitados devido a algum diagnóstico de transtorno mental, já que a gestão da incapacidade é uma ideia central no modo como as intervenções biopolíticas foram se produzindo historicamente.

A noção de biopolítica é retomada por Michel Foucault no curso ministrado no Collège de France de 1979, Nascimento da Biopolítica, como tecnologia de poder central na análise da construção e dos desdobramentos do capitalismo na sociedade contemporânea (Foucault, 2008). No curso, o autor dá sequência à análise dos modos de governamentalidade liberal, pensando sobre as racionalidades políticas nas quais foram inseridas as problemáticas específicas da vida e da população. A biopolítica, para o autor, se insere como uma tecnologia de poder que investe na vida, almejando buscar a eficácia máxima das ações do governo, mediante a intervenção na população (Foucault, 2005).

Em uma abordagem teórico-metodológica de base foucaultiana, o presente ensaio integra discussões na área da Psicologia Social e Institucional de 
matriz Pós-estruturalista. Nelas, a produção de conhecimento reivindica uma epistemologia própria, já que não é contemplada pelas perspectivas tradicionalmente abordadas (Hüning \& Scisleski, 2018). Com isso, um dos aspectos de suas produções é a análise de elementos da experiência do presente, para a produção de pensamentos e não de verdades forjadas, destacando a construção de um conhecimento particular, política e historicamente localizado (Ecker, 2018). Assim, as experiências aqui em análise, referidas as vivências da Pesquisa Pesquisa avaliativa de saúde mental: instrumentos para a qualificação da utilização de psicofármacos e formação de recursos humanos (Campos et al., 2012), possibilitaram a expressão de relatos de usuários e usuárias de serviços de saúde mental. Esses relatos, de modo particular, política e historicamente situados, serão contrapostos ao conceito de biopolítica como estratégia analítica das práticas de concessão do 'benefício' em saúde mental.

Para isso, no ensaio, em um primeiro momento, serão apresentadas especificidades dos processos do governo pelo INSS de legitimar incapacitados. Em um segundo momento, se apresentará o conceito de biopolítica, como modo de gestão governamental. Por fim, a partir de relatos de práticas com usuários(as) de serviços de saúde mental, serão descritos possíveis paradoxos em torno do processo de garantia do direito ao 'benefício' por invalidez. Esses paradoxos, serão contrapostos com reflexões sobre a produção de autonomias singulares e despatologizadas, como prevê os princípios da Reforma Psiquiátrica Brasileira.

\section{Trabalho como gerador de renda e biomarcadores de produtividade}

O Instituto Nacional do Seguro Social (INSS) é uma autarquia do Governo Federal do Brasil, vinculada ao Ministério da Previdência Social (MPS). O INSS recebe contribuições para a manutenção do Regime Geral da Previdência Social, sendo responsável pelos serviços previdenciários, como o pagamento de 'benefícios' previdenciários e 'benefício' assistencial para aqueles(as) que têm tal direito segundo o previsto em lei (Ministério da Previdência Social, 2017). Cabe ressaltar que o sistema da previdência é contributivo, tendo direito ao 'benefício' aquele que contribui de alguma forma ou depende de alguém que contribui ou contribuiu; enquanto o sistema da Assistência Social é seletivo por necessidade socioeconômica. São as seguintes modalidades: (i) benefícios previdenciários (contributivos): Aposentadorias (por idade urbana, por idade rural ou da pessoa com deficiência; por invalidez; por tempo de contribuição; por tempo de contribuição da pessoa com deficiência; especial); Auxílios (doença; acidente; reclusão); Salários (maternidade; familiar); Pensões (Talidomida; por morte); (ii) benefício assistencial (independem de contribuição): Benefício assistencial (ao idoso; ao deficiente) (Ministério da Previdência Social, 2017).

Quando alguém fica impossibilitado de exercer algum tipo de trabalho, seja permanente ou temporário, devido a complicações de ordem psíquica em geral, entende-se que há três principais modos de assegurar a obtenção de auxílios financeiros governamentais: auxílio doença ou aposentadoria por invalidez, se forem de ordem contributiva, e 'benefício' assistencial, para as pessoas sem vínculo empregatício ou sem contribuições, as quais serão incluídas na categoria de deficiência mental. A própria Constituição Federal de 1988 prevê, em seu artigo 203 inciso V, a garantia de um salário mínimo de 'benefício' mensal à pessoa portadora de deficiência que comprove não possuir meios de prover a própria manutenção ou de tê-la provida por sua família (Constituição da República Federativa do Brasil. 1988, 5 de outubro). Esse conteúdo está presente, também, no artigo 2, inciso IV da Lei Orgânica da Assistência Social (LOAS). 0 artigo 20 da LOAS, parágrafo 2 , especifica que é considerada pessoa portadora de deficiência aquela incapacitada para a vida independente e para o exercício do trabalho. No parágrafo 6, descreve que a concessão do 'benefício' ficará sujeita a exame médico pericial e laudos realizados por serviços próprios de perícia médica, com avaliação bianual acerca da continuidade das condições que lhe deram origem (Lei Orgânica da Assistência Social - LOAS, n. 8.742, de 7 de setembro de 1993, art. 21).

No caso do 'benefício' da assistência social, este é um recurso do Sistema Único da Assistência Social (SUAS), pago pelo Governo Federal, cujo direito é reconhecido pelo INSS e assegurado por lei, permitindo o acesso de pessoas com deficiência às condições mínimas de autonomia financeira para uma vida digna. Nesse caso, a pessoa precisa ter deficiência ou doença que a incapacite para o trabalho e para a vida independente (incapacidades decorrentes da deficiência/doença), ter renda familiar per capita inferior a $1 / 4$ de salário mínimo. Os critérios e a avaliação para considerar um portador de deficiência como incapacitado ${ }^{3}$, para a vida independente e para o trabalho, são realizados pelo serviço de perícia médica do INSS (Ministério da Previdência Social, 2017). 
Segundo informações do Ministério da Previdência Social (2017), a aposentadoria por invalidez é um direito dos(as) trabalhadores(as) que, por doença ou acidente, forem considerados(as) pela perícia médica da Previdência Social incapacitados(as) para exercer atividades ou serviços que lhes garantam o sustento. Não tem direito à aposentadoria por invalidez quem, ao se filiar à Previdência Social, já tiver doença ou lesão que geraria o 'benefício', a não ser quando a incapacidade resultar do agravamento da enfermidade. Para ter direito ao 'benefício', são exigidas 12 contribuições mensais, exceto na hipótese de acidente de qualquer natureza, de doença profissional ou do trabalho, que independe de carência. Quem recebe aposentadoria por invalidez deverá submeter-se à perícia médica de dois em dois anos para confirmar a permanência da incapacidade para o trabalho. A aposentadoria deixa de ser paga quando o segurado recupera a capacidade e/ou volta ao trabalho.

Já o auxílio-doença é um 'benefício' ao(a) segurado(a) que estiver incapacitado(a) para o trabalho. Para a concessão do 'benefício', é exigida a condição de segurado(a) e, na maioria dos casos, tempo de carência de contribuição. O segurado empregado e o trabalhador autônomo têm direito ao auxílio doença a partir da data do início da incapacidade. A incapacidade para o trabaIho deve ser comprovada através do exame médico-pericial da Previdência Social, sendo que o não comparecimento nesta avaliação implica no indeferimento do pedido (Ministério da Previdência Social, 2017). Cabe destacar que essas três políticas de Previdência Social se referem a aposentadorias ou a 'benefícios' que são concedidos a incapacitados(as).

\section{Produtividade, trabalho e perícia na trama biopolítica}

Michel Foucault, no curso ministrado no Collège de France de janeiro a abril de 1979, retorna ao conceito de biopolítica como um seguimento às discussões desenvolvidas em aulas anteriores, principalmente no que se refere ao processo de governamentalização da vida. A ideia de biopolítica foi introduzida nas análises de Foucault (2005), em meados da década de 1970, como nomeação da tecnologia de poder ser capaz de colocar em evidência os fenômenos do século $X X$ de estatização da vida biológica. Tendo o nazismo como experiência limite dessa prática, as discussões que envolvem a biopolítica possibilitam engendrar reflexões, estudos e pesquisas, sobre as condições do exercício político no contemporâneo, incluindo o que se produz pelas políticas públicas (Guareschi; Lara, \& Ecker, 2016).

Operar a partir da noção de biopolítica requer situar como a preocupação com a promoção e a preservação da saúde, especialmente a saúde do trabalhador, variou na história dos sistemas sociais e foi fortemente influenciada pelas revoluções liberais do século XVIII, que estruturaram solidamente o capitalismo, fazendo emergir tecnologias do Estado utilizadas a serviço do poder. Tais tecnologias, materializadas pelas políticas públicas, ocupam-se, não apenas, em disciplinar os corpos individuais, mas, também, em controlar o corpo social (Lazzarin, 2007). Nas palavras de Foucault:

[...] reger a multiplicidade dos homens ${ }^{4}$, não na medida em que eles se resumem em corpos, mas na medida em que ela forma, ao contrário, uma massa global, afetada por processos de conjunto que são próprios da vida, que são processos como o nascimento, a morte, a produção, a doença, etc. Logo, depois de uma primeira tomada de poder sobre o corpo que se fez consoante o modo da individualização, temos uma segunda tomada de poder que, por sua vez, não é individualizante mas que é massificante, se vocês quiserem, que se faz em direção não do homem-corpo, mas do homem-espécie. Depois da anátomo-política do corpo humano, instaurada no decorrer do século XVIII, vemos aparecer, no fim do mesmo século, algo que já não é uma anátomo-política do corpo humano, mas que eu chamaria de uma "biopolítica" da espécie humana (2005, p. 289).

Conforme explica Lazzarin (2007), os processos de governamento biopolítico são movimentos históricos que se produziram numa inversão do antigo direito de soberania de 'fazer morrer ou deixar viver' para 'fazer viver ou deixar morrer'. No primeiro caso, o soberano dispunha do direito de vida e morte sobre os súditos, já que a vida não era uma categoria política e as ações estatais desse período se voltavam, primordialmente, ao incremento das riquezas materiais e à extensão dos limites territoriais do reino. As vidas dos súditos, nesse momento, estavam à disposição do soberano porque, na medida em que o soberano tinha o dever e o interesse de protegê-las dos ataques de outros soberanos, também lhe era atribuído o direito de decidir sobre essas vidas, em caráter pleno.

Entre soberano e súditos se estabelecia uma relação de poder absoluta, protetora e ameaçadora, ao mesmo tempo. O súdito obedecia incondicionalmente ao soberano, porque tinha consciência 
que esse poderia matá-lo com a proteção da lei e da força pública. No entanto, o soberano era o único que detinha o aparato necessário para defender-se de possíveis ataques às suas posses. Dessa forma, não havia qualquer necessidade dele desenvolver políticas voltadas à proteção das vidas dos súditos; essas não lhe representavam, nem interesse, nem ameaça à estabilidade do poder que detinham (Lazzarin, 2007).

No Estado Moderno Liberal, no segundo caso, o poder deixa de ser voltado apenas ao disciplinamento dos corpos e torna-se direcionado a lógica da produtividade social advinda da aceleração dos fluxos sociais e econômicos. Assim, o Estado passa a ter cidadãos e não súditos. Uma governança, cujo regime de poder é fundado, não mais no controle do território, mas, no controle da população, como salienta Foucault (2005). A soberania muda seu status para o poder de assegurar as vidas. Agora, é a gestão da saúde, da higiene, da habitação, das ruas e avenidas, da alimentação, da natalidade, da sexualidade, da expressão, das trocas econômicas, que se convertem em novos desafios políticos dos poderes locais. Na nova formatação de inspiração biopolítica trata-se de "fazer viver e deixar morrer" (Foucault, 2005, p. 287).

Segundo Caponi (2012), o poder de soberania sofrerá um primeiro processo de acomodação com as tecnologias disciplinares, que são estratégias dirigidas aos corpos individuais destinadas a multiplicar as forças e capacidades de trabalho dos corpos, diminuindo sua força política. Um segundo processo de acomodação, para o autor, surgirá e se fortalecerá ao longo do século $\mathrm{XIX}$, sem excluir ou substituir a tecnologia disciplinar, mas, integrando-a e utilizando-a parcialmente para dirigir-se a um novo objeto de intervenção: "os processos biológicos e biossociológicos próprios dos fenômenos populacionais" (Caponi, 2012, p. 94).

Enquanto as disciplinas regulavam os corpos individuais, o novo poder biopolítico regula as vidas, tendo como objeto os sujeitos humanos enquanto seres vivos, enquanto espécie biológica. Lazzarin (2007) enfatiza que, embora a disciplina tenha sido eficiente em aplicar sobre os corpos humanos, por meio das instituições, táticas corretivas capazes de moldar os seus comportamentos individuais, não o fora tão exitosa em consumá-las, pois não conseguiu penetrar inteiramente na consciência e no corpo dos indivíduos. Com isso, emergem as estratégias biopolíticas, por um poder que deixa de ser apenas disciplinar, individualizante e de controle, e torna-se biopolítico, biológico e estatizante, permeando todo o corpo social a ponto de desenvolver-se virtualmente.
Com isso, a vida humana, que antes era desconsiderada pelo soberano, torna-se de interesse estatal na modernidade e, por isso, compõe-se enquanto objeto de uma política própria de proteção e conservação, como poderiam ser compreendidas as políticas públicas, por exemplo. Foucault (2008), ao buscar a história do liberalismo, aponta as condições neoliberais sob as quais o mercado agora se torna a instância de decisão e de manipulação da vida humana. O que antes era operado primordialmente pelo Estado, no liberalismo, será conduzido via mercado, no neoliberalismo, explica Foucault (2008). Apoiando-se na teoria do homo oeconomicus, o autor descreve como, via mercado, os sujeitos se tornam, não mais sujeitos de troca, mas, empresários, empresários de si mesmo. Desta forma, expressa:

Logo, chega-se à ideia de que o salário não é nada mais que a remuneração, que a renda atribuída a certo capital, capital esse que vai ser chamado de capital humano na medida em que, justamente, a competência-máquina de que ele é a renda não pode ser dissociada do indivíduo humano que é seu portador. [...] um dos interesses atuais da aplicação da genética às populações humanas é o de permitir reconhecer os indivíduos de risco e o tipo de risco que os indivíduos correm ao longo de sua existência (2008, p. 234).

Ao interpretar, teoricamente, as pessoas da modernidade enquanto capital humano, Foucault vislumbrou a conexão possível entre o homo oeconomicus do neoliberalismo, a teoria do capital humano e a biogenética, sem negar o componente eugênico e racista implicado na fusão entre reprodução humana e reprodução do capital. Nesse engendramento, a construção da noção de risco e de segurança se tornam racionalidades importantes no modo de governo biopolítico, especialmente, quando as pessoas alvo de intervenção são aquelas consideradas deficientes ou incapacitadas.

Uma tecnologia de poder com nuances biopolíticas, explica Caponi (2012), demanda a construção de saberes sobre as populações, como registros estatísticos e demográficos, a fim de possibilitar simbologias globais, índices comparativos, estabelecimento de médias, padrões de norma e de normalidade, cientificamente fabricados. Indicadores quantitativos, pensados de modo articulado a realidade econômica, constituem a base privilegiada a partir da qual serão construídas estratégias concretas de intervenção sobre as diferentes populações. Cálculos estatísticos de riscos e segurança fazem-se necessários, uma vez que há aumento dos fluxos das 
liberdades produzidas pelo neoliberalismo, demandando possíveis regulações. Regulações que, por sua vez, devem trazer, concretamente, segurança como contrapeso à quantidade de liberdade fabricada pelos poderes.

É nesse contexto, argumenta Lazzarin (2007), que a expressão biopolítica deve ser entendida como o âmbito do exercício instrumental do poder pelas instituições sociais, no sentido de extrair da vida humana o maior benefício possível de sua força produtiva, assim, tornando a diversidade humana em capital humano. O autor complementa que, nesse âmbito, a medicina do trabalho se desenvolveu e se afirmou enquanto prática almejada porque as condições de trabalho deveriam ser otimizadas, partindo das condições clínicas dos corpos dos indivíduos sobre os quais a biopolítica atua.

Cabe, portanto, à prática médica, incluindo a perícia médica, avaliar, analisar, medir a saúde dos empregados (L. A. Silva, 2011). Ao saber médico autoriza-se a palavra decisiva quanto à capacidade de trabaIho de cada funcionário(a). Pode-se observar, nessa questão, como se legitima pela técnica do exame uma profunda avaliação sobre as condições físicas e psíquicas do indivíduo, gerando registros sobre todas as particularidades dos corpos humanos como meio de verificar se eles são aptos, ou não, ao exercício da função laboral (Portaria n. ${ }^{\circ} 1.892$, de 09 de dezembro de 2013).

Produtividade, trabalho, perícia e legitimação da capacidade ou incapacidade tornam-se discursos engendrados que oficializam a tática dos exames de admissão, periódicos de manutenção durante o contrato de trabalho, ou de demissão, presente nas perícias médicas. Através desse engendramento, cumpre-se a função de separar, classificar, marcar o lugar que pode ou não ser ocupado pelo indivíduo, testando e legitimando sua capacidade/ incapacidade em ser produtivo. Essa sistemática, enquanto exercício biopolítico, permite manter sobre o corpo social um controle permanente, o qual se exerce no tempo cronológico do presente, passado e futuro.

\section{Paradoxos entre a afirmação de patologias versus ações de autonomização}

Ao ser apresentado o engendramento entre produtividade, trabalho e perícia, como estratégia biopolítica de gestão dos capazes/incapazes, compreende-se a importância do conceito de Biopolítica, proposto por Michel Foucault, para se problematizar os paradoxos em torno do processo de obtenção do 'benefício', via INSS, para sujeitos considerados incapacitados devido algum diagnóstico de transtorno mental. Assim, visando materializar esta discussão, serão apresentados relatos de usuários e usuárias de serviços de saúde mental como exercício de análise sobre suas relações com o 'benefício' e as condicionalidades.

Os relatos derivam da experiencia com usuários e usuárias de saúde mental, que se fizeram presentes ao longo dos quatro anos da pesquisa sobre a Gestão Autônoma da Medicação (Passos et. al., 2019. Os fragmentos analisados não se referem aos dados da pesquisa em si, mas, sim, a elementos da experiência que foram surgindo no encontro com pessoas que haviam recebido algum diagnóstico de transtorno mental e, ao longo dos anos da pesquisa, tiveram que passar pelo exame de avaliação do INSS. A vivência da perícia, mesmo que não fosse central no objetivo do estudo, tornava-se central na vida dos(as) usuários(as) que se viam interpelados e sob risco de perda do 'benefício' quando, em alguns casos, a recém iniciavam o processo de alta, melhora do adoecimento ou de desenvolvimento da autonomia.

Os relatos se tornaram mais presentes com a proximidade que se produziu entre todos os participantes da pesquisa, em outubro de 2013. Durante 15 dias, sete usuários de saúde mental, um familiar de usuário e duas estudantes de Pós-Graduação stricto sensu (Doutorado e Mestrado) estiveram na cidade de Montreal/CA. Essa viagem surgiu do desejo de usuários(as) de saúde mental brasileiros e canadenses em se encontrarem, desejo esse que constituiu a criação de um Encontro de Formação para que pudessem unir forças nas lutas por ações em saúde mental e ampliar as discussões acerca dos próprios direitos. Ambos os grupos compunham uma parceria institucional entre Brasil/Canadá ${ }^{5}$, desde 2010, encontrando-se através das ações do Projeto de Pesquisa Multicêntrico intitulado Pesquisa avaliativa de saúde mental: instrumentos para a qualificação da utilização de psicofármacos e formação de recursos humanos (Passos, Sade, \& Macerata, 2019).

Através dessa aproximação emergiram diversos relatos que criaram condições para colocar em análise os impasses produzidos entre os princípios propostos pela Reforma Psiquiátrica e os modos biopolíticos de gerir vidas através do sistema de classificação de invalidez do INSS. Relatos sobre o sistema de concessão do 'benefício' brasileiro como "preciso ser inválido para receber um benefício" [SIC], "provar ao INSS ser uma doença para ter acesso a um direito" [SIC], "ter tarefas sem ter remuneração" 
[SIC], remetiam a noção de biopolítica por situarem nos corpos um regimento de caráter global, de um Estado que regulamenta a gestão da doença na relação com a produtividade ou improdutividade dos sujeitos, enquanto espécie humana governada (Foucault, 2005).

Em consonância, exclamações significativas aos movimentos emancipatórios no campo da saúde mental como "sou uma pessoa, não uma doença" [SIC], apresentavam-se nos relatos dos próprios usuários(as), tensionando elementos do contexto de obtenção do 'benefício'. Ao buscarem, de forma organizada, operacionalizar os princípios da Reforma Psiquiátrica, pelas práticas de cuidado nas quais eram submetidos, usuários e usuárias expressavam afirmativas sobre o desejo de terem autonomia sobre a própria vida. Esse desejo se relacionava com uma ânsia por poder decidir sobre as escolhas de vida sem serem segregados, patologizados ou discriminados, por sua condição, conforme encontravam no artigo $5^{\circ}$ da Constituição Federal brasileira (1988, 5 de outubro): "todos são iguais perante a lei".

No entanto, para garantir Direitos Sociais básicos, que possibilitem exercícios de autonomia, o paradoxo dos 'benefícios' se apresenta sobre os corpos dos(as) usuários(as) em uma gestão que sobrepõe elementos patologizantes, ao mesmo tempo que garante um direito considerado especial:

Ele é chamado por muitos de vagabundo. Trabalhou formalmente por mais de uma década em uma mesma empresa. Nos últimos meses de trabalho, sentiu os impactos das crises psicóticas. Não conseguia trabalhar, desconfiava de tudo e de todos. Sua mãe o levou ao médico e lá ele recebeu o diagnóstico de esquizofrenia, com o qual pode buscar o auxílio-doença do INSS. As pessoas dizem que ele não tem doença alguma, que não trabaIha por vagabundagem. Se fosse doente, não participaria de movimentos sociais e nem atuaria em coletivos artísticos ou rádios comunitárias. Ele diz não se importar com os comentários. Responde que recebe o benefício porque necessita, porque tem direito, porque contribuiu [SIC].

Pela narrativa, se evidencia uma possível condicionalidade imposta ao sujeito, calcada em uma lógica biopolítica binária que, ou nomeia a pessoa como doente e incapaz para o trabalho, ou lhe impõe uma performance produtiva e o configura como um não merecedor do 'benefício'. Assim, a lógica do "fazer viver" biopolítico (Foucault, 2005) materializa na concessão do 'benefício' a exigência de uma vida permeada pela aceleração dos fluxos sociais e econômicos.
Essa aceleração, dentre suas imposições, exige das pessoas uma produtividade padronizada, calcada em padrões de capacidade, autonomia e independência. $O$ contexto de obtenção do 'benefício' não considera que, mesmo que as estratégias de cuidado em saúde mental incluam atividades de geração de renda e ocupacionais, essas operam em outra lógica de tempo e de quantificação produtiva, que não a de um humano "competênciamáquina" do capital (Foucault, 2008, p. 234).

O estudo de Barbosa, Martinhago, Hoepfner, Daré e Caponi (2016) sugere que, embora existam mudanças nas legislações das políticas de saúde mental no Brasil, que sugerem uma relação dos usuários com os serviços numa condição mais ativa, "as atividades ofertadas nos CAPs $^{6}$ ainda priorizam a medicalização e o atendimento individual", de cunho biopolítico normalizador, "em detrimento da oferta de tecnologias geradoras de maior autonomia" (p. 183). Complementa-se que, além da medicalização e individualização do sofrimento, os Projetos Terapêuticos Singulares, muitas vezes, inserem o trabalho e a produção de capital como parâmetro de tratamento, melhora ou cura. Assim, trabalho e patologia se unem como estratégias discursivas que exigem um determinado sujeito, tanto na produção de seu cuidado e tratamento, quanto na obtenção e manutenção do 'benefício' pelo INSS.

Compreende-se que as estratégias de controle operacionalizadas por uma lógica biopolítica fazem com que não seja mais necessário que um órgão externo diga que os 'incapazes ao trabalho não são capazes à vida': essa premissa se expressa pela subjetividade e no discurso dos familiares dos usuários, profissionais dos serviços e nos próprios usuários(as). Esses últimos, mesmo que reconheçam uma permanência do sofrimento, quando se tornam capazes de frequentar as atividades e apresentam sinais de saúde, ou uma melhor relação com os efeitos do adoecimento, culpam-se. Com isso, ficam receosos em perder a garantia de um salário mínimo, já que a categoria de transtorno mental que sustenta a manutenção do 'benefício' se torna mais tênue e diluída nos processos subjetivos usuais da vida. Em alguns casos, o receio de perder o 'benefício' pode resultar em uma intensificação do padecimento, já que o dinheiro recebido auxilia no mínimo para a garantia de uma qualidade de vida digna.

Segundo Zambillo (2015), a participação dos usuários de saúde mental em atividades de geração de renda, ocupacionais, práticas de cuidado de si, de falar por si e em projetos de pesquisa, assim como 
ações remuneradas, podem ser vias de autonomização. No entanto, ao perceberem que apresentam sinais de melhora, e que o 'benefícios' não garantem uma qualidade mínima de vida digna devido seu baixo valor, usuários e usuárias procuram meios de obter outras formas de renda. Nesse exercício de autonomia, o paradoxo que se materializa é o risco de que um sinal de saúde, o movimento autônomo, ameace o recebimento do 'benefício' e das aposentadorias, pois esses impossibilitam o acúmulo de outras rendas. Nesse paradoxo, tem-se o relato de um usuário do Centro de Atenção Psicossocial que, ao participar de diversas atividades do serviço, "sentia-se mais disposto" (SIC). Sua disposição, porém, levava-o a questionar o recebimento do 'benefício', uma vez que estar disposto fazia-o diferir do diagnóstico de depressão que lhe fora atribuído.

Assim, paradoxalmente, as atividades de cuidado que se pretendem emancipadoras colocam o usuário em um jogo de identidades fixadas pelo qual, ou ele é inválido ou não pode receber o benefício para se aposentar. Se a biopolítica pode ser pensada como uma política de proteção e conservação dos sujeitos (Foucault, 2008), paradoxalmente, no campo da saúde mental ela situa os processos biológicos e biossociológicos próprios dos fenômenos populacionais (Caponi, 2012) em uma tecnologia que fabrica paradoxos. Mesmo que receba apenas o auxílio-doença, ainda assim o indivíduo está lançado numa identidade de submissão ao diagnóstico que, se não lhe rouba a possibilidade do 'benefício', no mínimo coloca-o em contradição com as suas lutas, com a reivindicação de ser uma pessoa e não uma doença.

As práticas de exclusão, tão questionadas pelos movimentos da Reforma Psiquiátrica Brasileira, em torno da rotulação da loucura, parecem se reatualizar nos modos biopolíticos de gerir vidas na contemporaneidade ao inserirem o sistema econômico no contexto de distinção classificatória entre as pessoas nomeadas como 'capacitadas ao trabalho' e aquelas 'incapacitadas ao trabalho'. São rotulações positivadas, no sentido de validarem um direito (benefício, auxílio, aposentadoria) via instituição Estatal. Assim, ao mesmo tempo em que a vigilância clínica sobre o empregado pode ser entendida no sentido da negação e da submissão do trabalhador à empresa, numa relação de dominação e sujeição, a legislação trabalhista guarda também uma dimensão emancipatória, servindo como apoio para estabelecer uma relação menos injusta entre empregador e empregado.
Neste emaranhamento de forças, as relações de poder estão sempre em risco de se tornarem dominadoras e sepultarem as possibilidades de resistência dos usuários e usuárias dos serviços de saúde mental. Como lembra Lazzarin (2007), a lei trabalhista se justifica na necessidade de preservar a integridade física e mental do trabalhador. A obrigatoriedade da realização dos exames médicos, ao início, durante e ao fim do contrato de trabaIho, tem a finalidade de monitorar a saúde do trabalhador durante a sua vida laboral (Portaria n. ${ }^{\circ} 1.892$, de 09 de dezembro de 2013). Ela pode ser usada para captar elementos de prova, se for o caso, para demandar ações indenizatórias contra o empregador que, por conduta culposa, tenha contribuído para que a doença surgisse. Há poucos anos, o Ministério do Trabalho e Emprego (MTE) brasileiro estabeleceu a obrigatoriedade a todos empregadores e instituições que admitam "trabalhadores como empregados" de promover o Programa de Controle Médico de Saúde Ocupacional - PCMSO, "com o objetivo de promoção e preservação da saúde do conjunto dos seus trabalhadores" (Portaria n. ${ }^{\circ} 1.892$, de 09 de dezembro de 2013). Para Lazzarin (2007), isto exemplifica como o potencial humano de força produtiva passa a se qualificar em relação a bens materiais nas instituições em regime capitalista. Quer dizer, a preocupação com a promoção e a preservação da saúde do trabalhador se deve ao potencial de força produtiva que estes trabalhadores representam para seus empregadores. As eventuais patologias que forem detectadas neste processo podem tanto conferir direitos como provocar a exclusão social, dependendo de como se queira utilizar a informação obtida.

Disse-me que, depois de ter levado à falência seu próprio negócio, devido a uma série de crises psíquicas, fora diagnosticado com esquizofrenia. Relata que não quis o benefício do INSS, preferiu ir fazer outras coisas. Envolveu-se com pesquisas, com poesias, com músicas. Para a família, no entanto, era preciso que ele conseguisse fazer uma atividade que lhe rendesse algum dinheiro [SIC].

Nesse relato, ao dispensar o 'benefício' de incapacidade do seguro social, o usuário coloca-se em iminência de tentar equilibrar formas básicas de sobrevivência, como alimentação e moradia. Paradoxalmente, enquanto o 'benefício' devido a algum adoecimento psíquico deveria dar acesso a condições mínimas de sobrevivência àqueles que não podem trabalhar, no ritmo que exige o mercado de trabalho, ao mesmo tempo, as estratégias do INSS lançam os sujeitos nas malhas da vigilância. Essas, exigindo submissão à perícia 
de dois em dois anos, por exemplo, enquanto controle inescapável da biopolítica, não possibilita manter anônima qualquer particularidade de ser objetivado.

Frequentemente convidada para falar de sua experiência de vida em eventos sobre saúde mental ou em aulas nas universidades. Com ajuda de um colega, modera um grupo de ajuda-mútua. Não entende o por quê destes afazeres não serem remunerados $[\mathrm{SIC}]$.

Ainda que haja claramente a elucidação de uma atividade trabalhosa em alguns Projetos Terapêuticos, práticas de cuidado ou de pesquisa que envolvem usuários de saúde mental, as mesmas muitas vezes não são remuneradas. Isso ocorre porque, usualmente, as atividades remuneradas impõem um regime funcional de frequência e carga horária que parte dos usuários não dariam conta. As modalidades mais flexíveis e acolhedoras de trabalho sem grandes exigências de educação formal, por outro lado, não são capazes de subsidiar uma remuneração adequada. Tarefas possíveis para os usuários de saúde mental e pertinentes para a sociedade, como a elucidada no relato anterior, evidenciam a importância de uma articulação necessária entre a concessão de 'benefícios', sem a necessidade de patologização, e práticas de trabalho e de geração de renda singulares que deem conta das especificidades dos usuários e usuárias de serviços de saúde mental.

Segundo Vasconcelos (2000), na Suécia, uma das estratégias adotadas pelo governo local foi empregar mais de 150 usuários para trabalhar oito horas em serviços de auto-ajuda, tais como os clubes locais, totalmente controlados pelos usuários. Além disso, mediante aliança feita com o movimento dos deficientes, os usuários de saúde mental deliberaram assumirem-se como deficientes para terem acesso a uma série de direitos especiais, tais como 'benefícios' de renda, acesso às habitações e esquemas especiais de trabalho. Apesar de não se sentirem confortáveis sendo chamados de deficientes, nesse caso, vemos a adoção de diagnóstico psiquiátricos como premissa para os(as) usuários(as) terem acesso ao que se chama 'salário subsidiado', pelo qual o empregador recebe um subsídio do governo e ganha um salário comum de mercado.

Em relação ao paradoxo biopolítico, entre reivindicar direitos especiais e lutar pelos Direitos Civis e Sociais (contra o estigma, a discriminação e a tutela), o movimento europeu, explica Vasconcelos (2000), busca saídas por meio de uma tática principal: justificar os direitos especiais pelo fato de os usuários terem sido vítimas do sistema psiquiátrico. No entanto, para evitar fixação em apenas essa identidade, o movimento procura expressar a diferença de forma positiva: os usuários são pessoas mais sensíveis ${ }^{7}$, que passam por experiências existenciais mais radicais. Trata-se de uma posição intermediária entre os dois pólos (direito à igualdade e à diferença). Muito próximo ao que coloca Santos (2010, p. 56): "temos direito de sermos iguais quando as diferenças nos inferiorizam, e temos o direito de sermos diferentes quando as igualdades nos escravizam". Esta constitui a tática chamada 'discriminação positiva', que também vem sendo usada em relação a outras minorias sociais, no campo paradoxal da lógica biopolítica.

\section{Considerações finais}

Ao ser proposto este ensaio, com o objetivo de problematizar os paradoxos em torno dos 'benefícios' governamentais cedidos aos indivíduos considerados incapacitados ao trabalho devido algum diagnóstico em saúde mental, pode-se utilizar o conceito de Biopolítica de Michel Foucault $(2005 ; 2008)$ contrapondo-o a relatos de usuários e usuárias de serviços de saúde mental. No debate, articulando trabalho, produtividade, adoecimento e os diagnósticos psiquiátricos, foi possível colocar em análise alguns dos paradoxos em torno do processo de obtenção do 'benefício' do INSS, via governo, que oscila entre conceder direitos e patologizar os sujeitos pelos métodos e condicionalidades utilizados.

Com isso, materializando lógicas biopolíticas na gestão das pessoas, a inclusão dos transtornos mentais no campo das negociações econômicas envolve diversas disputas de poder entre especialistas, governo e movimentos sociais em prol dos princípios da Reforma Psiquiátrica Brasileira. Essas disputas se tornam evidentes na prática da perícia médica do INSS, por exemplo, onde a interpretação das informações transmitidas pelo trabalhador para a decisão médica-pericial assemelha-se a um julgamento. Como diz Severo (2009), quando o poder se configura como fiscalização e não mais como punição e castigo, o saber científico é operado como estratégia. Assim, o 'benefício', paradoxalmente, situa a reivindicação pelos direitos das pessoas em sofrimento mental em operacionalidade que, ao mesmo tempo em que beneficia os usuários e usuárias, reforça o estatuto de tutelados e do poder do diagnóstico (psiquiátrico/ psicológico) como critério de garantia dos mesmos.

Essa lógica paradoxal biopolítica dos direitos se torna ainda mais intensa quando as reivindicações 
emancipatórias no campo da subjetividade estão localizadas numa sociedade em que os Direitos Sociais previstos em Constituição não foram conquistados pela maioria da população, como é o caso do Brasil. Assim, se os 'benefícios' governamentais e aposentadorias se colocam de forma paradoxal é, também, porque boa parte da população brasileira não tem Direitos Sociais garantidos e precisa obter alimentação, moradia, saneamento básico, saúde, educação, dentre outros, à custa da manutenção de patologias como justificativa para ter direitos ou o próprio sistema desigual se torna adoecedor.

Assim, no tensionamento da categoria capacitado/incapacitado, mesmo acometidos por algum adoecimento, existem diversas atividades nas quais os usuários de saúde mental poderiam se vincular, mesmo que essas não se enquadrassem nos modelos clássicos de trabalho remunerado como historicamente fora instituído pelos modos biopolíticos de gerir vidas no ocidente. A exemplo da experiência sueca trazida no texto, parece possível substituir a categoria de deficiência mental (atualmente entendida como deficiência intelectual) por outras compreensões, que afirmem singularidades existenciais, requerendo outros modos de organizar vidas e impor produtividades.

Portanto, há que se levar em consideração, ainda que num regime capitalista, as particularidades laborais de cada pessoa para que as exigências de produtividade se adaptem às especificidades de cada sujeito, sem tornarem-se motivo de adoecimento dos mesmos. Na produção de exercícios de autonomia, dos usuários e usuárias dos serviços de saúde mental, necessita-se relativizar os critérios de incapacidade, abandonando o binarismo biopolítico dos capazes/incapazes, para afirmação das diferentes nuances de possibilidades produtivas de cada caso acompanhado. Com isso, dar-se-ia segmento às conquistas cidadãs iniciadas pela Reforma Psiquiátrica Brasileira, permitindo que a população atendida vislumbre outros modos de vínculos trabalhistas possíveis. Isso inclui pensar um sistema de seguridade e de assistência social que contemple em suas legislações e políticas lógicas de proteção social que levem em consideração diferentes subjetividades, sem a necessidade de limitar autonomias ou de patologizar as pessoas.

\section{Referências}

Barbosa, V. F. B., Martinhago, F., Hoepfner, Â. M. S., Daré, P. K., \& Caponi, S. N. C. (2016). O cuidado em saúde mental no Brasil: uma leitura a partir dos dispositivos de biopoder e biopolítica. Saúde em Debate, 4O(108), 178-189. doi: 10.1590/0103-1104-20161080015
Campos, R.T.O.etal.(2012).Adaptação multicêntrica de um guia paraa gestão autônoma da medicação. Interface: Comunicação, Saúde, Educação, Botucatu,(16), 43, 967-980. doi: 10.1590/S1414-32832012005000040

Caponi, S. (2012). Classificar e medicar: a gestão biopolítica dos sofrimentos psíquicos. Revista Internacional Interdisciplinar INTERthesis, 9(2), 101-122. doi: 10.5007/1807-1384.2012v9n2p101

Constituição da República Federativa do Brasil (1988, 5 de outubro). Recuperado de http://www.senado.gov.br/sf/legislacao/const/

Ecker, D. D. (2018). Direitos sociais e acompanhamento terapêutico: problematizações através de desenhos. Aurora: Revista de Arte, Mídia e Política, 11(32), 95-109. Recuperado de http://revistas.pucsp.br/ index.php/aurora/arti cle/view/31984/26874

Ferrazza, D. A., \& Peres, W. S. (2016). Medicalização do corpo da mulher e criminalização do aborto no Brasil. Fractal: Revista de Psicologia, 28(1), 17-25. doi: 10.1590/1984-0292/1016

Foucault, M. (2005). Em defesa da sociedade. Curso no Collège de France (1975-1976) (M. Ermantina, Trad.) Galvão. São Paulo: Martins Fontes.

Foucault, M. (2008). Nascimento da biopolítica. Curso no Collège de France (1978-1979) (E. Brandão, Trad.). São Paulo: Martins Fontes.

Guareschi, N. M. F.; Lara, L., \& Ecker, D. D. (2016). A internação compulsória como estratégia de governamentalização de adolescentes usuários de drogas. Estudos de Psicologia, 21(1), 25-35. doi: 10.5935/1678-4669.20160004

Hüning, S. M., \& Scisleski, A. C. C. (2018). Ressonâncias de uma epistemologia foucaultiana em psicologia social. Psicologia \& Sociedade, 30, e170632. doi: 10.1590/1807-0310/2018v30176687

Lazzarin, J. F. (2007). Os dispositivos de poder e a construção da subjetividade do excluído em Michel Foucault: Implicações jurídicas e desafios sociais. (Dissertação de Mestrado, Universidade do Vale do Rio dos Sinos, São Leopoldo, RS). Recuperado de http://www.repositorio.jesuita.org.br/handle/UNISINOS/2027

Lei n. 10.216, de 6 de abril de 2001 (2001, 6 de abril). Dispõe sobre a proteção e os direitos das pessoas portadoras de transtornos mentais e redireciona o modelo assistencial em saúde mental. Brasília, DF: Presidência da República. Diário Oficial da União, seção 1. Recuperado de http://www.planalto.gov.br/ccivil_03/leis/leis_2001/l10216.htm

Lei Orgânica da Assistência Social - LOAS, n. 8.742, de 7 de setembro de 1993 (1993, 7 de setembro). Dispõe sobre a organização da Assistência Social e dá outras providências. Brasília, DF: Presidência da República. Recuperado de http://www.planalto.gov.br/ccivil_03/ leis/L8742compilado.htm

Lemos, F. C. S., Cruz, F. F., Reis Junior, L. P., Sampaio, V., Cruz, A. P.C., \& Côrrea, M. R. (2015). Biopolítica, gênero e organismos internacionais: mercado dos direitos das mulheres. Fractal: Revista de Psicologia, 27(3), 203-210. doi: 10.1590/1984-0292/1478

Ministério da Previdência Social. (2017). Informações sobre benefícios. Instituto Nacional do Seguro Social. Brasília, DF: Presidência da República. Recuperado de https://portal.inss.gov.br/informacoes/

Onocko Campos, R. T; Passos, E; Leal, E; Palombini, A. L; Serpa Jr., O. D., Emerich, B. F., ... Carvalho, J. (2012). Guia da gestão autônoma da medicação - GAM. Recuperado de http://www.fcm.unicamp.br/ $\mathrm{fcm} /$ laboratorio-saude-coletiva-e-saude-mental-interfaces

Passos, E., Sade, C. \& Macerata, I. (2019). Gestão Autônoma da Medicação: inovações metodológicas no campo da saúde pública. Saúde e Sociedade, 28(4), 6-13. doi: 10.1590/s0104-12902019000004

Portaria n. ${ }^{\circ}$ 1.892, de 09 de dezembro de 2013 (2013, 09 de dezembro). NR 7 - Programa de controle médico de saúde ocupacional. Brasília, DF: Ministério do Trabalho e do Emprego. 
Paradoxos nos 'benefícios' aos incapacitados: biopolítica e saúde mental

Santin, G., \& Klafke, T.E. (2011). A família e o cuidado em saúde mental. Barbarói, 34(1), 146-160. doi: 10.17058/barbaroi.v0i34.1643

Santos, B. S. (2010). Reconhecer para libertar: os caminhos do cosmopolitanismo multicultural. Introdução: para ampliar o cânone do reconhecimento, da diferença e da igualdade. Rio de Janeiro: Civilização Brasileira.

Severo, A. K. S. (2009). A cronificação nos serviços substitutivos na rede de saúde mental de Natal/RN (Dissertação de Mestrado, Universidade Federal do Rio Grande do Norte, RN). Recuperado de https://repositorio.ufrn.br/jspui/handle/123456789/18674

Silva, L. A. (2011). Saúde e Trabalho na educação: micropolítica dos discursos (Dissertação de Mestrado). Recuperado de https://www.lume. ufrgs.br/bitstream/handle/10183/29677/000778443.pdf?sequence $=1$
Silva, T. T. (2016). A biopolítica do corpo feminino em estratégias contemporâneas de ativismo digital. Revista Estudos Feministas, 24(3), 739-759. doi: 10.1590/1806-9584-2016v24n3p739

Vasconcelos, E. M. (2000). Reinvenção da cidadania, Empowerment no campo da saúde mental e estratégia política no movimento de usuários. In P.Amarante (Org.), Ensaios: subjetividade, saúde mental, sociedade [online] (pp.169-194). Rio de Janeiro: FIOCRUZ. Recuperado de http://books.scielo.org/id/htjgj/pdf/amarante-9788575413197-10.pdf

Zambillo, M. (2015). Autonomias errantes: entre modos de ser autoimpostos e possibilidades de invenção de si (Dissertação de Mestrado, Programa de Pós-Graduação em Psicologia Social e Institucional, Universidade Federal do Rio Grande do Sul). Porto Alegre: RS. Recuperado de http://hdl.handle.net/10183/134693

1. Este ensaio deriva da Pesquisa *autora. Pesquisa financiada com bolsa de Mestrado pela Coordenação de Aperfeiçoamento de Pessoal de Nível Superior (CAPES). Maiores informações, consultar: Zambillo (2015).

2. No texto, mantêm-se a palavra 'benefício' entre apóstrofes como estratégia de desnaturalização dessa categoria, propondo indagações como: benefício em relação a que? Para quem? Com qual objetivo? Sob qual ponto de vista?

3. O termo incapacitado e derivados são utilizados pelo próprio INSS e pela lei. Optou-se por não usar as aspas nesse caso, para não confundir o leitor com estratégias de pontuação excessivas, mas poder-se-ia questionar a ideia de incapacidade com as mesmas indagações propostas no termo 'benefício': incapaz em relação a que? Para quem? Com qual objetivo? Sob qual ponto de vista?

4.A tradução do livro de Michel Foucault utiliza a palavra "homens", quando se refere aos processos anátomo-políticos do século XVIII. Compreende-se que o uso da palavra homens possa representar um momento histórico, em que a maioria das mulheres não possuíam os mesmos Direitos Sociais e possibilidades de liberdade, mas, cabe afirmar o discurso sexista presente nessa tradução. Sobre mulheres, feminino e biopolítica, sugere-se: (Ferrazza \& Peres, 2016; Lemos et al., 2015; T. T. Silva, 2016).

5. Parceria estabelecida entre Brasil e Canadá, através do Projeto Pesquisa avaliativa de saúde mental: instrumentos para a qualificação da utilização de psicofármacos e formação de recursos humanos com financiamento de agência de fomento canadense, a Alliance de Recherche Universités Communautés Internationale - Santé Mentale et Citoyenneté/Aliança Internacional de Pesquisas Universidades-Comunidades - Saúde Mental e Cidadania (ARUCI-SMC), e apoio do CNPq (Passos, et al., 2019).

6. Centro de Atenção Psicossocial (CAPs).

7. Essa constitui a mesma tática do movimento negro americano, quando defende que "black is beautiful" (negro é maravilhoso) (Vasconcelos, 2000, tradução nossa).

Marciana Zambillo, Mestre em Psicologia Social e Institucional pela Universidade Federal do Rio Grande do Sul, é doutoranda na mesma instituição. Endereço para correspondência: Instituto de Psicologia, UFRGS. Rua Ramiro Barcelos, 2600 - Santa Cecilia, Porto Alegre - RS, 90035-003, sala 136. E-mail: marcianazambillo@gmail.com

Analice de Lima Palombini, Doutora em Saúde Coletiva pela Universidade Estadual do Rio de Janeiro, é professora na Universidade Federal do Rio Grande do Sul. E-mail: analice.palombini@gmail.com

Daniel Dall'Igna Ecker, Mestre em Psicologia Social e Institucional para Universidade Federal do Rio Grande do Sul, é doutorando na mesma instituição. E-mail: daniel.ecker@hotmail.com 